Preprint: final version available from

AdAms, A. \& BlandFord, A. (2002) Digital libraries in academia: challenges and changes. In E-P Lim, S. Foo, C. Khoo, H. Chen, E. Fox, S. Urs \& T. Costantino (Eds.) Digital Libraries: People, Knowledge, and Technology. 392 - 403. Springer LNCS 2555.

\title{
Digital libraries in academia: challenges and changes
}

\author{
Anne Adams ${ }^{1}$, and Ann Blandford ${ }^{2}$ \\ ${ }^{1}$ Research institute for digital libraries (RIDL), Middlesex University, Trent Park, \\ London, UK. N14 4YZ \\ a.adams@mdx.ac.uk \\ http://www.cs.mdx.ac.uk/RIDL/aadams/default.html \\ ${ }^{2}$ UCL interaction centre, 26 Bedford way, \\ London, UK. WC1H 0AB \\ a.blandford@ucl.ac.uk \\ http://www.uclic.ucl.ac.uk/annb/
}

\begin{abstract}
Although web accessible digital libraries (DLs) have greatly increased potential information accessibility within academia, the use of these resources varies widely across disciplines. This study, within contrasting departments (Humanities, Computing and Business) of a London university, reviews the social and organisational impacts of DLs across these disciplines. In-depth interviews and focus groups with 25 lecturers and librarians were conducted, and analysed using the grounded theory method. Web-accessible DLs are identified as changing the roles and working patterns of academic staff (i.e. lecturers, librarians and computer support staff). However, poor accessibility due to inappropriate implementation strategies, access mechanisms, searching support \& DL usability reduces the use of these resources. Consequently, web and personal collections without guarantees of quality are widely used as an accessible alternative. One conclusion is the importance of implementation strategies (e.g. giving feedback on document context, collection boundaries, ownership, accountability and support) in informing DL design.
\end{abstract}

\section{Introduction}

In the past academic libraries were totally bound by their physical parameters. Library users initiated the interactions by going to the library. They physically walked around the library and searched or browsed for their information, or asked a librarian for help. When successful, they read or took the hard copy information out of the library. This 
model supported a wide variety of users from many different disciplines. With the introduction of library technology those physical boundaries have slowly changed. The searching was done via microfiche or CDROMs then information was either photocopied or read in the library online (e.g. via CDROMs or Library IP based computers).

With the advent of web-accessible digital libraries and remote authentication (e.g. Athens password), users' physical interaction with the library could completely change. Digital libraries (DLs) have the potential to transform aspects of the education process, with remote access to specialized information in a format that is easily updated and speedy searching and access facilities. However, the invisible presence of these resources, their poor usability and user support has made their impact less dramatic $[6,16]$. A key element in the successful design and implementation of digital libraries has, in the past, been identified as their social context $[7,8,9]$. The social contexts of organisational systems can have important impacts on the community involvement in resulting technology systems [10]. The role of the librarian and the changing impact of DLs across all the academic disciplines although crucial have not been fully researched. This paper presents the findings from an in-depth analysis of lecturer and librarians' perceptions within contrasting disciplines and the impact of digital libraries within those social contexts. The resulting design implications for digital libraries are also presented.

\subsection{Background}

Digital libraries (DLs) are a major advance in information technology that frequently falls short of expectations $[8,17,11]$. Crabtree et al [9] identified problems with digital libraries through research into physical academic library interaction patterns with regard to information searching strategies. There are two principal aspects of their findings:

1. the importance of collaboration between the librarian and the user in the searching activity, and

2. the significance of social context in digital library design.

However, Crabtree et al [9] concentrated on one aspect of library interaction (i.e. information searching) within the confines of a physical library and with library assistants rather than subject librarians. Covi \& Kling [8] argue that understanding the wider context of usage is essential to understanding digital library use and its implementation in different social worlds. Negative reactions to digital libraries are often due to inappropriate system design and poor implementation $[1,2,7]$. However, there may be other less obvious social and political repercussions of information system design and deployment. Symon et al [15] have identified, within a clinical setting, how social structures and work practices can be disrupted by technology implementation. Although academic DL systems do not deal with sensitive, personal information apparently innocuous data can be perceived as a threat to social and political stability $[1,2]$. There are several accounts that detail the importance of social context for digital library design and implementation $[7,8]$ To understand the impact of DLs 
within academia, an in-depth evaluation is required of the implementation and use of these applications across disciplines within their specific social and organisational settings. However, as Covi \& Kling [8] have highlighted, there are few high-level theories that aid designers in understanding the implication of these issues for DL design and implementation.

\subsection{Social Context and Roles}

DL research increasingly focuses on the importance of directing DL design towards the work practices and communities they support [12,8]. Covi and Kling's [8] research into patterns of usage for DLs within an academic context identified the importance of roles within effective DL design. A parallel study to this research completed within the clinical domain identified that DL technology was perceived as a threat to senior staff members' roles due to their poor training and support [1,2]. Traditional organisational norms and roles were reversed by DLs allowing junior clinicians easier access to information than senior clinicians.

It is also important to understand user informal practices and how they interact within organisational dynamics, changing situations, evolution of task definitions, or social and political aspects (e.g. staff motivation, hierarchies). Adams \& Sasse [3] found that systems that do not take into account these practices and are perceived to restrict them would be circumvented. DL designers must therefore design their systems around user practices, understanding both social and organisational norms. The electronic dissemination of information within various settings can be used and interpreted in politically sensitive ways. Digital libraries, in particular, can change the context of people's work-practices and can therefore restructure their relationships with both each other and the task in hand $[13,15]$. The restructuring of these professional relationships can have far-reaching social and political consequences. Ultimately, system designers should be aware of social and political motivations within an organization in order to develop and implement more sensitive design strategies.

\section{Research Method}

Focus groups and in-depth interviews were used to gather data from 25 academics and librarians from 4 different campuses within a London university. 10 of those interviewed were from Humanities, 10 from Computer Science and 4 from Business with the split of the sample being approximately 50\% librarians / academics. The final respondent was from a key managerial role within library services. The academics were selected from all levels within their department (i.e. lecturer, Senior Lecturer, Reader, Professor). There was a representative sample from each department of teaching and non-teaching staff. Of the 13 librarians interviewed, the majority were subject librarians with authorization to acquire and support digital resources for their discipline. 
Four issues guided the focus of questions:

- Perceptions of their role within the academic setting and information requirements.

- Perceptions of how information is currently accessed, and how these processes accommodate or inhibit current working practices.

- The impact of organisational social structures and patterns of interaction on information resource awareness, acceptance and usage.

- Technology perceptions (specifically of DLs) and how these affect other issues already identified.

A pre-defined concept for a 'Digital Library' was not employed so that users were allowed to explore what they perceived comprises a digital library. This resulted in a discipline distinction between the different definitions given to similar electronic resources (a summary of these can be seen in the results). Although various electronic resources were reviewed three main DLs were discussed; the ACM DL, PROQUEST and LEXUS.

An in-depth analysis of respondents' information and technology perceptions was conducted using the Grounded Theory method. Grounded Theory [14] is a socialscience approach to data collection and analysis that combines systematic levels of abstraction into a framework about a phenomenon which is verified and expanded throughout the study. Once the data is collected it is analysed in a standard Grounded Theory format (i.e. open, axial and selective coding and identification of process effects). Compared to other social science methodologies, Grounded Theory provides a more focused, structured approach to qualitative research (closer in some ways to quantitative methods) [14]. The methodology's flexibility can cope with complex data and its continual cross-referencing allows for grounding of theory in the data thus uncovering previously unknown issues. 


\section{Results}

The results identified different perceptions about electronic resources not only between disciplines but also, more importantly, between the librarians and the lecturers. Key to these differences were the current and past roles of the library and how lecturers and students interacted with it. Web-based digital libraries, while alleviating most library resource and interaction problems, require a change in the librarians' role if they are to be implemented effectively. Without this role change, lecturers and students were found to have a poor awareness and understanding of digital resources and resorted to the web and online personal collections as an accessible alternative. Finally DL interactions were marred by their design and inadequate support. Many digital libraries were found to be inappropriately designed according to users needs, marginalizing their importance in the educational process for students and researchers.

\subsection{Digital Resource Perceptions}

Initially, as already detailed, the respondents' perceptions of and definitions for a wide range of electronic resources were identified. The results showed that, with slight variations, the users had a uniform perception of what a digital library, a database, and an archive were. The definition of a DL usually included that they were a large store of general but up-to-date information in various media with current usage. However, an archive was invariably denoted as a subject specific historical collection with clearly defined parameters, which is not in current use. A database was described by most as a way of structuring and organizing information, which could be accessed either by CDROM, local networks or the web. One librarian added that a database contained only summarized, abstract or citation information while a digital library contained the full text.

An analysis (using normalized data) of how often the users referred to different terms for resources within the interview is shown in Table 1. There were some interesting differences in how often the librarians and lecturers from different disciplines commented on these resources. A divergence can be seen between electronic resources discussed within the interviews by lecturers and librarians. Computer science and business lecturers referred to similar electronic resources as 'digital libraries' while in humanities they were identified as 'archives'. However, the librarians invariably referred to all these resources as 'databases'.

It may be noted that the library web site (see Figure 1) reflects the librarians' database terminology without any reference to digital libraries or archives. Several of the digital libraries are located under the headings 'databases' and 'journals, despite (in the case of, for example, the ACM digital library) storing more than journal publications.

Table 1. Percentage of each digital resource referred to by users.

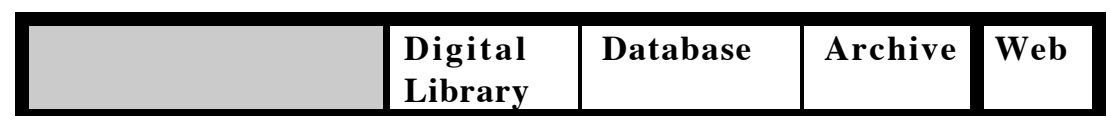




\begin{tabular}{|l|c|l|l|l|}
\hline Lecturers \\
\hline $\begin{array}{l}\text { CS / B usiness } \\
\text { lecturing }\end{array}$ & $\mathbf{3 1 \%}$ & $10 \%$ & $6 \%$ & $53 \%$ \\
\hline Humanities lecturing & $7 \%$ & $3 \%$ & $\mathbf{3 2 \%}$ & $58 \%$ \\
\hline Librarians & \multicolumn{4}{|l|}{} \\
\hline CS / Business librarian & $17 \%$ & $\mathbf{3 5 \%}$ & $24 \%$ & $24 \%$ \\
\hline Humanities librarian & $3 \%$ & $\mathbf{6 6 \%}$ & $3 \%$ & $28 \%$ \\
\hline
\end{tabular}

Figure 2. Library resource interface.

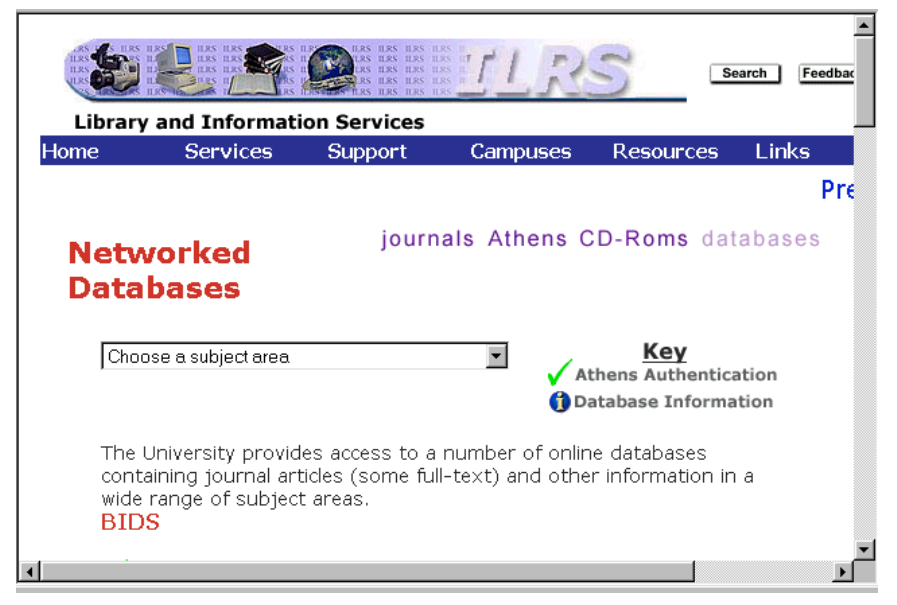

Many of the resources under the title 'networked databases' were then identified in the description on the site as digital libraries (e.g. Medline, EBSCO).

\subsection{Current and Changing Roles}

The results showed that lecturers tend to perceive the librarians as being tied to books and hard copy resources. For example:

"They would keep the list of the recommended books with them; if there was Internet URL's then they would print them out and put those in the library as well."

(CS lecturer - teaching)

It was highlighted by some that library systems also reflected this book-orientated approach:

"... if they go into the library and they punch into the machine I want something on this subject and it will come up with some books in that area because of the keywords in the title or keywords in that area. It won't come up with journal articles."

(Humanities senior lecturer - teaching / research) 
Ultimately some library users perceived that the librarians were centred on and possessive of the resources rather than supporting and understanding the users:

“... the librarians are not user-centred they're information resource centred ... they want to protect their resources not to gain access to them."

(CS lecturer - teaching / research)

The subject librarians, when detailing their role, always mentioned resource acquisition as the first priority in their job role, and then training. Few highlighted the marketing or on-going support for electronic resources:

"Provision of materials which involves book selection, journal selection and I suppose even online resource selection ... A major part of our work is on library education." (CS librarian)

The perceived roles of librarians were identified as relating to current interaction patterns between lecturers, librarians and students. Interactions between librarians and lecturers or students occurred primarily within the physical boundaries of the library. Lecturers and librarians interacted on an informal ad-hoc basis either by 'bumping into' one another (primarily in the library) or by direct instigation from the lecturers or students themselves. Library instigated interactions were email based usually regarding hard-copy resource acquisitions or discontinuation:

"But I haven't spoken to a librarian directly for at least 3 years."

(CS lecturer - teaching / research)

"I filled in an email two days ago if that counts saying what was good and bad journals. But no, not on the whole. We send in our requests for books." (CS lecturer - teaching / research)

Within the humanities department some interactions became more pro-active with librarians arranging meetings with the lecturers. However the interactions were always focused on the students and course requirements. Librarians across all the departments were not perceived as identifying and supporting the lecturers' own needs, while some lecturers noted that they needed to know more:

"It's an area of enormous ignorance for me. If I knew more, I would know better how to advise people."

(Humanities senior lecturer - teaching)

The librarians often discussed training sessions, but these tended to centre on student training, as the lecturers were notoriously bad at attending these sessions. It was suggested by librarians across the disciplines that this was because the lecturers were embarrassed by their poor electronic resource skills:

"So if you're running one on medieval studies - the medieval lecturer will come and sit at the back of the class and you know that they're not trying to keep an eye on their class, they're trying to actually learn without appearing not to know." (Humanities librarian)

The library department has, over recent years, employed an electronic resource librarian (a new position within the university). Although the job specification is yet to be clarified the role concentrates on electronic resources across disciplines but is confined to one of the university's many sites. The job requires a more pro-active interaction with the lecturers (e.g. attending research group meetings to promote 
current electronic resources, organizing external training from DL providers) than that of a subject librarian. It was this librarian that highlighted the different demands on librarians in terms of supporting the user required by electronic resources as opposed to print resources.

There is a perception that some librarians may have problems changing to this role. However, the benefits from this change were evident from these results. Only one lecturer interviewed reported having received information about current systems available. This lecturer was based at the electronic resource librarians' site.

The results also showed that DL resources require more interaction between the library and other departments (e.g. IT Support) necessitating further role changes:

"... now there is also a bit of a barrier with the computing staff about whether they should be bothered with this ... they're loathe to see that their role is also changing." (Electronic resource librarian)

With current roles and interaction patterns, students who needed support have to leave their searches wherever they are (e.g. computer room) and go to the library to seek advice.

In summary, the roles and expectations of students, teaching staff, librarians and IT support staff are all being forced to change as digital libraries and similar resources are introduced.

\subsection{Digital Libraries or the Web}

As can be seen from table 1, lecturers across the disciplines frequently note the importance of the web as an electronic resource. The CS lecturers, in particular, highlighted the importance of using the web as the main supplement to core books. However, it was noted that the level of plagiarism from the web had dramatically increased over recent years. It was also found that students have very poor skills in searching and identification of reputable sources. Lecturers and librarians were both seeking to address these inadequacies with training to improve searching and information discerning skills. Neither the lecturers nor librarians mentioned the benefits of DLs (i.e. guaranteed reputable resources, discipline focused) as opposed to the web. Lecturers frequently commented about the attractiveness of the web for both themselves and the students. The mystical and consumable qualities of searching the web were identified as key incentives. Web searching and a wide variety of web resources were noted as an easy consumable that led the user towards large quantities of information for relatively little effort:

"Some people when they use search engines they type in a question and if they don't get the answer that they are looking for they type in another one. Just like prayers"

(CS lecturer - teaching / research)

"I mainly use Amazon for books a lot. I find the books and download and print off the summaries for the students"

(CS Professor - research) 
Ultimately, the lecturers had poor awareness of what digital libraries were available via the web or subscribed to by the university:

"no like advice, certainly no tailoring of information from the library

service." (Humanities senior lecturer - teaching)

Several of the humanities lecturers, for example, suggested that a useful digital resource would be an online newspaper archive so that the students did not have to travel to the physical newspaper library to complete their research. However, all the librarians noted the successful acquisition of this same resource for the past year. This example highlights the importance of not only acquiring the right resources but also adequately marketing them. The main library approach to marketing these resources was by links on the library web-page, induction courses, word of mouth or handouts within the library:

"We explain about it at the skills session they get and we have sheets at the desk that we give out." (humanities librarian)

"When new staff come in we make them aware of the databases that are available which we think they'll probably like in their subject area." (CS librarian)

A survey conducted by the library department, however, had shown that few lecturers knew about the library web site. Also, both the students and lecturers were found to rarely attend the library.

"Problems with students - they just tend to be library phobic." ( C S

lecturer - teaching)

"And they don't really use it [the library] themselves [lecturers]. Because they use the same journal articles every year. So in that sense there is no, very little connection between academics and us."

(Humanities librarian)

\subsection{Digital Library Design to Support User Needs}

Even if lecturers were aware of digital library resources their poor design relative to user needs discouraged usage. Some humanities lecturers, for example, noted that they needed to see the whole page of a newspaper, including advertising and other articles to assess advertising and marketing strategies undertaken. However, most newspaper digital libraries assume that only content is important and that even this does not have to remain accurate to the printed version (i.e. specific electronic versions). This makes the resource an inadequate replacement for hard-copy versions. However, this same discipline was eager to gain access to digital libraries for a variety of multimedia resources (e.g. visual media, television programmes, films, music) that are not currently being provided.

Other digital formatting issues related to hyperlinks within documents. For some disciplines this can aid in effective information gathering. However, in disciplines where the flow of the content is important (e.g. literature, journalism) hyperlinks can be a disadvantage: 
"The only thing I worry about with the digitising of works are the way that it changes our interpretation of the documents. I've seen it with our students as soon as you have something on the web with hyper-links they read the information in a different way. Speed reading and focusing in on the keywords that will take them forward to further information. Their own interpretations of the document are taken out of their hands and moulded by the person who digitised the document rather than the author." (Humanities reader teaching / research)

Whatever the disciplines, there were continual references to reading large quantities online being difficult, and printing expensive:

"Most people if they're going to do it, serious reading, download it and print it off." (CS senior lecturer - teaching)

"The sort of texts they need to have access to are widely available and the quantity we expect them to look at would be a problem as far as reading them on a computer or expensive to print up."

(Humanities Reader - teaching / research)

Another issue that arose with all the digital libraries across the disciplines was one of poor usability and support for infrequent users. Many of the interfaces were identified as continually changing so a gap in usage meant relearning the system, which sometimes outweighed the benefits of its usage:

"So it doesn't encourage students or staff to use it because unless you're using it every week you lose it. So if you don't go into it for a couple of weeks you've lost it." (Humanities librarian)

"You have to keep training every year, every 6 months. It's not static" (CS librarian)

Even frequent users argued that they were often lost when interfaces changed without notification or links to support in re-learning the new interface:

"I mean the other thing about ACM and many of the other databases is that they don't even tell anyone about it - they just change it. ACM just went and you couldn't get into it there were all these phone calls what's happened to the ACM we can't get into it. And the other thing was they didn't answer anyone. They didn't tell anyone and then they wouldn't answer back to queries." (Electronic resource librarian)

Some in library services summarized the design problem succinctly:

"Electronic libraries and digital libraries in the UK very seldom descends to looking at the way that these things might be used, how they might fit into people's work patterns and needs. So far we have been inventing tools and then trying to find markets for them rather than doing the market research and then providing the right tools."

(Library management)

The importance of a pro-active role across the departments supporting and understanding the users' needs is evident from this research. However, understanding users' needs requires increased communication and collaboration to aid in an understanding of 
potential successful and unsuccessful implementation strategies. Ultimately, as one lecturer pointed out, there is no communication from the library about strategies that they might be taking. This respondent identified this as due to the culture of library systems as a whole:

"Because librarians have the skill or disability of making difficult answers." (CS lecturer - teaching / research)

\section{Discussion}

Bishop's [4] study into DL users from different social and economic backgrounds found that they can be easily deterred from DL usage and that poor awareness of library coverage prevents a full understanding of DL potential. The findings detailed in this paper have highlighted the importance of organisational roles and interaction patterns. Lecturers were found to have a poor awareness of DLs available as well as an understanding of their potential. They were also found to be deterred from using these resources because of poor relevance to their needs, support and usability for infrequent users. A link was identified between these issues and the current poor interaction model in place between lecturers and librarians. The disparity between librarians' and lecturers' attention to different electronic resources highlights diverse perceptions of information resources.

A key factor in the poor interaction patterns between librarians and lecturers, to which they referred frequently in interviews, was their ad hoc, informal nature. While these patterns may have, in the past, been effective, the perceived benefits of online resources have initiated a change in users' requirements from librarians and library resources. Whether librarians are or are not conceptually bound to books, it is important to highlight that across the disciplines lecturers' requirements are not. Lecturers are, however, inadequately aware of what electronic resources are available, and require support in their learning and use of these facilities [4]. The driving force for the changing role of librarians should be the attractive yet unreliable reputation of web information. Students can be lured into this fantasy information consumable world and, without lecturers acquiring the knowledge to guide them towards DLs, the impact of the web will increasingly dominate academic resource use. Ultimately, the librarians' role must change into one that is more pro-active and flexible - for example, attending small research group meetings and helping to develop and support the resources that the users need. The feedback to and from the developers and users must provide the information and contextual knowledge that each requires [9]. The increased importance of electronic resources also means a role change for IT support, with increased collaboration required between IT and library services.

Finally, the design and implementation of DLs should cater for the discipline differences that were clearly highlighted by these results. For example, the importance of context and full text original documents required by the humanities will not be fulfilled if systems are designed to present content only via the abridged hyper-linked documents required by other disciplines [5]. 


\section{Conclusion}

This research has highlighted how related social and organisational issues can impede effective technology deployment. To counteract these problems, DL designers and implementers must first identify the social context prior to technology design and deployment $[7,8,9,10]$. There is a need within this context to increase the awareness of digital resources available and their potential within specific academic contexts and disciplines [9]. There is also a need to strongly supporting training for some lecturers with a supportive and non-judgemental approach [1,2]. Ultimately, lecturers and students need the services of an information expert role to support and inform them.

\section{References}

1. Adams, A. \& Blandford, A.: Acceptability of medical digital libraries. In the Health Informatics Journal (2002) 8 (2) 58 - 66.

2. Adams, A \& Blandford, A.: Digital libraries in a clinical setting: friend or foe. Proceedings of ECDL'2001 Springer (2001) 231-224

3. Adams, A. \& Sasse, M. A.: The user is not the enemy. In Communications of ACM. ACM Press (Dec. 1999) $40-46$

4. Bishop, A. P.: Making Digital Libraries Go: Comparing Use Across Genres. Proceedings of ACM DL '99, ACM Press (1999) 94-103.

5. Bishop, A. P.: Digital Libraries and Knowledge Disaggregation: The Use of Journal Article Components. Proceedings of ACM DL'98, ACM Press (1998) 29-39.

6. Blandford, A., Stelmaszewska, H. \& Bryan-Kinns, N.: Use of multiple digital libraries: a case study. Proceedings of JCDL'01, ACM Press (2001) 179-188.

7. Caidi, N.: Technology and values: Lessons from central and Eastern Europe. Proceedings of JCDL'01, ACM Press (2001) 176-177.

8. Covi, L. \& Kling, R.: Organisational dimensions of effective digital library use: Closed rational and open natural systems model. In Kiesler, S (ed) Culture of the Internet. Lawrence Erlbaum Associates, New Jersey (1997) 343-360

9. Crabtree, A., Twindale, M., O'Brien, J. and Nichols, M.: Talking in the library: Implications for the design of digital libraries. Proceedings of DL'97, ACM Press (1997) 221-228.

10. Kling, R.: What is social informatics and why does it matter? D-lib Magazine, (1999) 5(1), January. www.dliborg/dlib/january99/k/ing/01/<lmg.hgml

11. Marchionini, G. \& Maurer, H.: The roles of digital libraries in teaching and learning. In Communications of ACM, ACM Press (April. 1995) 67 - 75

12. Marchionini, G., Nolet, V., Williams, H., Ding, W., Beale Jr., J., Rose, A. Gordon, A., Enomoto, E. and Harbinson, L.: Content + Connectivity $\Rightarrow$ Community: Digital Resources for a learning community. Proceedings of ACM DL'97, Philadelphia, ACM Press (1997) 212-220 
13. Schiff, L., Van House, N. \& Butler, M.: Understanding complex information environments: a social analysis of watershed planning. Proceedings of ACM DL'97, Philadelphia, ACM Press (1997) 161-168

14. Strauss, A. \& Corbin, J.: Basics of qualitative research: grounded theory procedures and techniques. Sage, Newbury Park (1990)

15. Symon, G., Long, K \& Ellis, J.: The Coordination of work activities: cooperation and conflict in a hospital context. Proceedings of Computer supported cooperative work, ACM Press (1996) 5 (1) 1-31

16. Theng, Y.L., Duncker, E., Mohd Nasir, N., Buchanan,G. \& Thimbleby, H.: Design guidelines and user-centred digital libraries. In Abiteboul, S. \& Vercoustre, A.(Eds.), Proceedings of ECDL'99 (1999) 167 - 183.

17. Wyatt, J.: The clinical information access project, New South Wales: lessons from a NeLH precursor. In proceedings of Advances in clinical knowledge management, Presented at ACKM 3 (2000) 